\title{
Din Kültürü ve Ahlak Bilgisi Öğretmenlerinin Eğitim Bilişim Ağı'na (EBA) İlişkin Tutumları
}

Attitudes of Religious Culture and Ethics Teachers Towards Education Informatics Network (EBA)

\section{Mehmet YILDIZ}

Dr., Milli Eğitim Bakanlığı, Kadıburhaneddin İmam Hatip Ortaokulu

Dr, Ministry of Education, Kadıburhaneddin Imam Hatip Secondary School

Sivas/TURKEY

mehhmetyildiz@hotmail.com

http://orcid.org/0000-0002-4548-0648

Doi: 10.34085/buifd.1012322

\section{Bu Araştırma; Sivas Cumhuriyet Üniversitesi'nin 02/04/2021 tarih ve 29071 Sayılı Etik İzin Onayı İle Yapılmıştır.}

Öz

Son yıllarda öğrencilerin öğretim ortamına aktif bir şekilde katıldığı, görsel ve işitsel e-içeriklerle bireysel öğrenmelerin desteklendiği çevrimiçi platformlar yaygınlaşmaya başlamıştır. Bu çerçevede ülkemizde "Fırsatları Artırma ve Teknolojiyi İyileştirme Hareketi" (FATİH) projesi kapsamında 2012'de "Eğitim Bilişim Ağg1" (EBA) kurulmuştur. EBA'da örgün eğitimde yer alan tüm derslerle ilgili, her sınıf seviyesinde doğru ve güvenilir eiçerikler sunulmakta ve öğretmenlere içerik hazırlama imkânı tanınmaktadır. EBA'da din öğretimine yönelik olarak Din Kültürü ve Ahlak Bilgisi öğretmenlerinin kullanabileceği içeriklere de yer verilmektedir. Bu çalışmada Din Kültürü ve Ahlak Bilgisi öğretmenlerinin EBA'ya ilişkin tutumlarının cinsiyet, yaş, hizmet yılı, çalışılan okul türü ve mezun olunan yükseköğretim programı değişkenlerine göre incelenmesi amaçlanmaktadır. Nicel araştırma türünde olan çalışmada ilişkisel tarama modeli kullanılmıştır. Araştırma verileri, ülke genelinde görev yapan Din Kültürü ve Ahlak Bilgisi öğretmenleri içerisinden, uygun örnekleme yöntemiyle belirlenen 315 öğretmenden anket tekniğiyle toplanmıştır. Araştırmada veri toplama aracı olarak Uğurlu ve Gürsoy tarafından geliştirilen "Eğitim Bilişim Ağı Tutum Ölçeği” kullanılmıştır. Araştırma verileri SPSS 25 programıla analiz edilmiştir. Çalışmada ulaşılan sonuçlara göre Din Kültürü ve Ahlak Bilgisi öğretmenlerinin EBA'ya ilişkin tutumları olumludur. Öğretmenlerin tutumlarında cinsiyet, yaş, çalışılan okul türü ve mezun olunan yükseköğretim programı değişkenlerine göre anlamlı bir farklılık oluşmamıştır. Hizmet yılı düşük olan öğretmenlerin daha olumlu tutuma sahip olduğu görülmüştür.

Anahtar Kelimeler: Din Eğitimi, Din Kültürü ve Ahlak Bilgisi, Eğitim Bilişim Ağı, EBA, Tutum

\section{Abstract}

In recent years, online platforms have become widespread, where students actively participate in the teaching environment and individual learning is supported with visual and auditory e-contents. In this context, the "Education Informatics Network" (EBA) was established in 2012 within the scope of the "Movement to Increase Opportunities and Improve Technology" (FATIH) project in our country. In EBA, accurate and reliable e-contents are offered at all grade levels regarding all courses in formal education, and teachers are given the opportunity to prepare content. EBA also includes content that can be used by Religious Culture and Moral Knowledge teachers for religious education. In this study, it is aimed to examine the attitudes of Religious Culture and Moral Knowledge teachers towards EBA according to the variables of gender, age, years of service, type of school and graduated higher education program. The relational survey model was used in the study, which is in the type of quantitative research. The research data were collected by questionnaire technique from 315 teachers determined by convenient sampling method among the Religious Culture and Moral Knowledge teachers working throughout the country. "Education Information Network Attitude Scale" developed by Uğurlu and Gürsoy was used as a data collection tool in the research. Research data were analyzed with SPSS 25 program. According to the results obtained in the study, the attitudes of Religious Culture and Moral Knowledge teachers towards EBA are positive. There was no significant difference in the attitudes of the teachers according to the variables of gender, age, type of school and graduated higher education program. It has been observed that teachers with low years of service have more positive attitudes.

Keywords: Religious Education, Religious Culture and Moral Knowledge, Education Information Network, EBA, Attitude 


\section{GíRiş}

Son yıllarda gerçekleşen teknolojik gelişmeler, hayatın birçok alanıyla birlikte eğitim alanında da etkisini göstermektedir. Dinamik bir süreç olan eğitimin teknolojik gelişmelere göre şekillenmesi elbette kaçınılmaz bir durumdur. Özellikle bilişim teknolojilerindeki gelişmeler, eğitimde kullanılan araçların çağa ayak uyduracak şekilde yenilenmesini gerekli kılmıştır. Başlangıçta TV, tepegöz, projeksiyon gibi teknolojik araçların kullanıldığı eğitim faaliyetlerinde, son yıllarda yaygınlaşan bilgisayar, akıllı tahta, tablet gibi araçlarla birlikte, öğrencinin öğretim ortamına aktif bir şekilde katıldığı, görsel ve işitsel e-içeriklerle bireysel öğrenmelerin desteklendiği çevrimiçi platformlar kullanılmaya başlanmıştır. Eğitim teknolojilerindeki bu gelişmeler, ülkemizde yürütülen eğitim faaliyetlerine de yansımıştır. ${ }^{1}$ Bu kapsamda Milli Eğitim Bakanlığı (MEB) tarafından ülkemizdeki eğitim teknolojilerini güncelleştirmeye yönelik birçok proje ve uygulama hayata geçirilmiştir. Bu proje ve uygulamalar içerisinde en çok ön plana çıkan ise vizyon 2023 kapsamında 2011'de hayata geçirilen Fırsatları Artırma ve Teknolojiyi İyileştirme (FATIH) projesi olmuştur. ${ }^{2}$

FATIH projesi, teknolojik imkânlardan yararlanarak eğitimde fırsat eşitliğini sağlamak ve kaliteli eğitim içerikleriyle öğrencilere iyi bir eğitim imkânı sunmak amacıyla başlatılan büyük ve kapsamlı bir eğitim hareketidir. Fatih projesiyle, okullardaki teknolojik imkânların artırılması ve etkili öğrenmeyi sağlamak amacıyla eğitim sürecinde bilişim teknolojilerinden etkin bir şekilde yararlanılması hedeflenmiştir. Bu hedef çerçevesinde öğrencinin, dersteki başarısının yanı sıra, ilgi alanlarının, aktivitelerinin ve eğilimlerinin de değerlendirilebilmesine ve böylece onun tüm öğrencilik hayatıyla ilgili verinin analiz edilerek ilgi ve başarı alanına göre mesleğe yönlendirilebilmesine imkân tanıyacak bir alt yapı oluşturulması planlanmıştır. ${ }^{3}$ Beş ana bileşenden oluşan proje kapsamında öğretmen ve öğrencilerin ihtiyaç duydukları ders materyallerinin çevrimiçi olarak sunularak eğitsel e-içeriğin sağlanması amacıyla MEB Yenilik ve Eğitim Teknolojileri Genel Müdürlüğü (YEĞITEK) tarafından 2012'de Eğitim Bilişim Ağı (EBA) kurulmuştur.

EBA, kullanıcıları için tüm sınıf seviyelerinde müfredatla uyumlu ders içerikleriyle birlikte, kişisel ve mesleki gelişim içeriklerini kişiselleştirilmiş ve güvenilir olarak sunan çevrimiçi ve sosyal bir eğitim platformudur. Okullarda okutulan derslerin her biri için ayrı bir alanın bulunduğu EBA'da, her bir ders için zengin, etkileşimli ve güvenilir içerik bulunmaktadır. Her ders için ders kitabı, etkileşimli kitaplar, testler ve uygulamalarla birlikte, derslerin konu ve kazanımlarıyla eşleştirilmiş videolu ya da etkileşimli konu anlatımları, alıştırmalar, infografikler ve farklı tarzlarda sorular da EBA'da sunulmaktadır. Ayrıca öğretmenler EBA'ya görsel, işitsel ve yazılı içerik ekleme ve EBA üzerinde içerik oluşturma imkânına da sahiptir. Bu içeriklerin yanı sıra çizgi film, okuma kitabı, eğitsel oyun, belgesel, röportaj, dergi gibi farklı kategorilerde içeriğin yer aldığı; öğretmen, öğrenci ve velilerin kişisel gelişimlerine katkı sağlayacak zengin bir kütüphane alanı da EBA'da yer almaktadır. Kişiselleştirilmiş yapısıyla öğrenciye özel bir ara yüz ve içerik sunan EBA, akıllı öneri sistemi sayesinde öğrencinin performansına göre içerik önerisinde bulunabilmektedir. Ayrıca sosyal bir eğitim platformu olmasından dolayı EBA üzerinden öğrenciler ve öğretmenler birbirleriyle etkileşim içerisinde olabilmektedirler. Her kullanıcı kişisel duvarından ileti paylaşabilme, tartışma ve oylama yapabilme ve mesajlaşabilme imkanına da sahiptir. Öğretmenler EBA üzerinden öğrencilerine çalışmalar gönderebilmekte ve öğrencinin çalışmalara ve EBA kullanımına yönelik performansını takip edebilmektedir. ${ }^{4}$ 2019'da Çin'de ortaya çıkan, 2020'de ülkemizi de etkileyen Covid 19 salgını nedeniyle salgının seyrine göre zaman zaman yüz yüze eğitime ara verilmiş, uzaktan eğitime geçilmiştir. Uzaktan eğitimin önem kazandığı bu süreçte EBA daha da işlevsel hale gelmiş ve uzaktan eğitim yapılabilen bir özelliğe kavuşturulmuştur.

Tüm dersler gibi Din Kültürü ve Ahlak Bilgisi (DKAB) dersine yönelik içeriklere de EBA'da yer verilmektedir. Hem ilkokul, hem ortaokul hem de lise düzeyindeki DKAB dersine yönelik görsel, işitsel ve yazılı içeriğe sahip olan EBA, DKAB öğretmenlerinin de kullandığı bir platformdur. Yapılan

\footnotetext{
${ }^{1}$ Zafer Çakmak - Cengiz Taşkıran, "Sosyal Bilgiler Öğretmenlerinin Perspektifinden Eğitim Bilişim Ağı (EBA) Platformu”, Uluslararası Türk Ĕ̆itim Bilimleri Dergisi 2017/9 (2017), 285.

${ }^{2}$ Ozan Coşkunserçe - Gökçe Becit İşçitürk, “Eğitim Bilişim Ağı (EBA) Platformu Hakkında Öğrencilerin Farkındalığının Artırılmasına Yönelik Bir Durum Çalışması”, Eğitimde Nitel Araştırmalar Dergisi 7/1 (2019), 261.

${ }^{3}$ Milli Eğitim Bakanlığı (MEB), “Fatih Projesi” (Erişim 17 Nisan 2021).

${ }^{4}$ MEB, "Fatih Projesi".
} 
araştırmalarda EBA'yı kullanmaya yönelik yeterli bilgiye sahip olduklarını düşünen DKAB öğretmenleri, dersin verimliliğini arttırmak, eksik olan içeriği desteklemek, derste teknolojiden

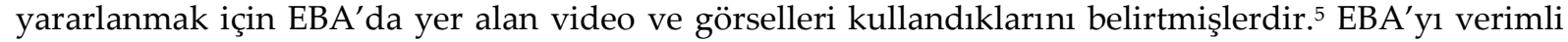
bir platform olarak gören DKAB öğretmenleri, ${ }^{6} \mathrm{DKAB}$ dersine yönelik EBA'da yer alan içeriğin yetersiz olduğu görüşündedirler. ${ }^{7}$ Bu çalışmada DKAB öğretmenlerinin EBA'ya ilişkin tutumları ve bu tutumlarının cinsiyet, yaş, hizmet yılı, çalışılan okul türü ve mezun olunan yükseköğretim programı değişkenlerine göre incelenmesi amaçlanmaktadır. Bu amaç çerçevesinde aşağıdaki sorulara cevap aranmıştır:

1. DKAB öğretmenlerinin EBA'ya ilişkin tutumlarının düzeyi nedir?

2. DKAB öğretmenlerinin EBA'ya ilişkin tutumları cinsiyet, yaş, hizmet yılı, çalışılan okul türü ve mezun olunan yükseköğretim programına göre farklılaşmakta mıdır?

EBA'ya ilişkin yapılan araştırmalar incelendiğinde, DKAB dersi özelinde yapılan iki araştırmaya ulaşılmıştır. Bu araştırmaların her ikisi de nitel türde olup az sayıda katılımcıyla yapılmıştır. Her iki araştırma da DKAB öğretmenlerinin EBA'ya yönelik görüşlerini incelemeye yöneliktir. Bu araştırmalarda ulaşılan sonuçlara göre DKAB öğretmenlerinin büyük çoğunluğunun daha çok görsel ve işitsel dokümanlara ulaşmak için az da olsa EBA'yı kullandı̆̆ı, EBA'yı yararlı verimli olarak görmelerine rağmen içerik olarak yetersiz bulduğu, EBA'yı kullanabilme konusunda kendilerini yeterli gördüğü ortaya çıkmıştır. ${ }^{8}$ Alan yazında DKAB öğretmenlerinin EBA'ya ilişkin tutumlarını belirlemeye yönelik bir çalışmaya rastlanmamıştır. Bu yönüyle araştırma özgün bir çalışmadır. Branş bazında ayrım yapmadan öğretmenlerin EBA'ya ilişkin tutumlarının belirlendiği bazı çalışmalar yapılmıştır. ${ }^{9}$ Bu çalışmalarda ulaşılan sonuçlara, çalışmamızın sonuçlarıyla ilişkilendirilerek ilerde değinilecektir. Uzaktan eğitimin değer kazandığı bir dönemde, DKAB öğretmenlerinin uzaktan eğitim sürecinde kullanılan platformlardan biri olan EBA'ya ilişkin tutumlarının tespit edildiği bu çalışmanın alana katkı sağlayacağı düşünülmektedir.

\section{Yöntem}

\subsection{Araştırmanın Modeli}

DKAB öğretmenlerinin EBA'ya ilişkin tutumlarının incelendiği bu çalışma tarama modelinde betimsel bir çalışmadır. Tarama modeli, geçmişte ya da halen var olan bir durumu var olduğu şekliyle betimlemeyi amaçlayan araştırma modelidir. Bu modelde araştırılmak istenen konu ya da olay, doğal ortamında ve olduğu gibi tanımlanır. ${ }^{10}$ Toplanan verilerle bir grubun belirli özelliklerinin tespit edilmeye çalışıldığ $1^{11}$ tarama modelinde verilerin toplanmasında çeşitli araçlar kullanılır. Betimsel çalışmalarda en çok kullanılan veri toplama tekniği anket ve mülakattır. ${ }^{12}$

\subsection{Evren ve Örneklem}

\footnotetext{
${ }^{5}$ Teceli Karasu, “İmam Hatip Meslek ve DİKAP Dersi Öğretmenlerinin Eğitim Bilişim Ağı (EBA) İle İlgili Görüşleri” 7/2 (2018), 938; Gökçe Becit İşçitürk - Emine Zehra Turan, “Din Kültürü ve Ahlak Bilgisi Öğretmenlerinin Eğitim Bilişim Ağı'na İlişkin Görüşleri", Turkish Studies 13/29 (2018), 43.

${ }^{6}$ Karasu, “İmam Hatip Meslek ve DİKAP Dersi Öğretmenlerinin Eğitim Bilişim Ağı (EBA) İle İlgili Görüşleri”, 940.

${ }^{7}$ Becit İşçitürk - Turan, “Din Kültürü ve Ahlak Bilgisï Öğretmenlerinin Eğitim Bilişim Ağı'na İlişkin Görüşleri”, 44.

${ }^{8}$ Bkz. Becit İşçitürk - Turan, "Din Kültürü ve Ahlak Bilgisï Öğretmenlerinin Eğitim Bilişim Ağı'na İlişkin Görüşleri", 35-45; Karasu, “İmam Hatip Meslek ve DİKAP Dersi Öğretmenlerinin Eğitim Bilişim Ağı (EBA) İle İlgili Görüşleri”, 925-943.

${ }^{9}$ Behice Varışoğlu, “Öğretmenlerin Eğitim Bilişim Ağı (EBA) Tutumlarının İncelenmesi”, Turkish Studies-Social Sciences 14/6 (2019), 3511-3521; Şeyma Bayyiğit Teker, Öğretmenlerin Teknolojik Pedagojik Alan Bilgisi (TPAB) Yeterlilikleri İle Ĕ̆itim Bilişim A $\breve{g} l$ (EBA) Kullanımına Yönelik Tutumları Arasındaki Ilişski (Balıkesir: Balıkesir Üniversitesi, Fen Bilimleri Enstitüsü, Yüksek Lisans Tezi, 2019); Beytullah Aztekin, Öğretmenlerin Eğitim Bilişim Ağğna Yönelik Farkındalık Düzeyleri Ve Tutumlarn Arasındaki İlişkinin İncelenmesi (Zonguldak: Zonguldak Bülent Ecevit Üniversitesi, Sosyal Bilimler Enstitüsü, Yüksek Lisans Tezi, 2020); Murat Şireci, Öğretmenlerin EBA Tutumlarının Farklı Değişsenler Açısından İncelenmesi (Kahramanmaraş: Kahramanmaraş Sütçü İmam Üniversitesi, Fen Bilimleri Enstitüsü, Yüksek Lisans Tezi, 2021).

${ }^{10}$ Niyazi Karasar, Bilimsel Araştırma Yöntemi (Ankara: Nobel Yayın, 2014), 77.

${ }^{11}$ Şener Büyüköztürk vd., Eğitimde Bilimsel Araştırma Yöntemleri (Ankara: Pegem Akademi, 2019), 15.

${ }_{12}^{2}$ Saim Kaptan, Bilimsel Araştırma ve İstatistik Teknikleri (Ankara: Tekışık, 1998), 61.
} 
Araştırmanın evreni 2020-2021 eğitim öğretim yılının 2. döneminde ilkokul, ortaokul ve liselerde görev yapan $44587^{13}$ DKAB öğretmenlerinden oluşmaktadır. Örneklem ise evren içerisinden olasılık dışı örnekleme türlerinden uygun örnekleme yöntemiyle ${ }^{14}$ belirlenmiş 315 DKAB öğretmeninden oluşmaktadır. Bulabildiğini örnekleme de denilen uygun örneklemede kolaylıkla bulunabilen örneklem birimleri kullanılır. Uygun örneklemede örneklemin temsil düzeyini tahmin etme olasıllı̆ı yoktur. Örneklem büyüklüğü için kesin bir sayı söz konusu değildir. ${ }^{15}$ Çok değişkenli analizlerin yapılabilmesi için örneklem büyüklüğünün, değişken sayısının 5 katından fazla olması gerekir. ${ }^{16} \mathrm{Bu}$ bağlamda örneklemin yeterli temsil düzeyine sahip olduğu kabul edilmiştir. Örneklemi oluşturan katılımcıların kişisel özelliklerine göre dağılımı Tablo 1'de belirtilmiştir.

Tablo 1. Araştırmaya Katılan DKAB Öğretmenlerinin Kişisel Özellikleri

\begin{tabular}{|c|c|c|c|}
\hline \multicolumn{2}{|r|}{ Kişisel Özellikler } & $\mathbf{N}$ & $\%$ \\
\hline \multirow[t]{3}{*}{ Cinsiyet } & Kadın & 172 & $\overline{54,6}$ \\
\hline & Erkek & 143 & 45,4 \\
\hline & Toplam & 315 & 100 \\
\hline \multirow[t]{5}{*}{ Yaş } & $21-30$ & 100 & 31,7 \\
\hline & $31-40$ & 129 & 41 \\
\hline & $41-50$ & 61 & 19,4 \\
\hline & 51 ve Üzeri & 25 & 7,9 \\
\hline & Toplam & 315 & 100 \\
\hline \multirow[t]{7}{*}{ Hizmet Yılı } & 15 & 96 & 30,5 \\
\hline & 610 & 102 & 32,4 \\
\hline & 1115 & 56 & 17,8 \\
\hline & 1620 & 26 & 8,3 \\
\hline & $21-25$ & 12 & 3,8 \\
\hline & 26 ve Üzeri & 23 & 7,3 \\
\hline & Toplam & 315 & 100 \\
\hline \multirow[t]{4}{*}{ Çalışılan Okul Türü } & İlkokul & 13 & 4,1 \\
\hline & Ortaokul & 239 & 75,9 \\
\hline & Lise & 63 & 20 \\
\hline & Toplam & 315 & 100 \\
\hline \multirow{6}{*}{$\begin{array}{l}\text { Mezun Olunan } \\
\text { Yükseköğretim Programı }\end{array}$} & Yüksek İslam Enstitüsü & 2 & 0,6 \\
\hline & Eski İlahiyat Fakültesi & 168 & 53,3 \\
\hline & İlahiyat Fakültesi DKAB Bölümü & 72 & 22,9 \\
\hline & Eğitim Fakültesi DKAB Bölümü & 55 & 17,5 \\
\hline & Yeni İlahiyat/İslami İlimler Fakültesi & 18 & 5,7 \\
\hline & Toplam & 315 & 100 \\
\hline
\end{tabular}

\subsection{Verilerin Toplanması ve Analizi}

\footnotetext{
${ }^{13}$ Bu sayı, Eğitime Bakış 2018: İzleme ve Değerlendirme Raporu'nda belirtilen 35211 sayısına, raporun yayınlanmasından sonra ataması yapılan DKAB öğretmenlerinin sayısının ilavesiyle elde edilmiştir. Bekir S. Gür vd., Eğitime Bakış 2018: İzleme ve Değerlendirme Raporu (Ankara: Eğitim Birsen Stratejik Araştırmalar Merkezi, 2018$), 93$.

${ }^{14}$ Sevgi Yıldız, "Sosyal Bilimlerde Örnekleme Sorunu: Nicel ve Nitel Paradigmalardan Örnekleme Kuramına Bütüncül Bir Bakış", Kesit Akademi Dergisi 3/11 (2017), 430; Büyüköztürk vd., Eğitimde Bilimsel Araştırma Yöntemleri, 95.

${ }^{15}$ Karasar, Bilimsel Araştırma Yöntemi, 127.

${ }^{16}$ Yalçın Karagöz, SPSS ve AMOS 23 Uygulamalı İstatistiksel Analizler (Ankara: Nobel, 2016), 284.
} 
Araştırmada veri toplama aracı olarak Uğurlu ve Gürsoy tarafından geliştirilen ${ }^{17}$ Eğitim Bilişim Ağı (EBA) Ölçeği, yazarlarından gerekli izin alınarak kullanılmıştır. 5’li likert olarak geliştirilen ölçek, iki alt boyuta sahip olup ve 30 maddeden oluşmaktadır. Ölçekten alınabilecek en yüksek puan 150, en düşün puan $30^{\prime}$ dur. Ölçeğin geçerlik ve güvenirlik çalışması yapılmıştır. EBA'nın gerekliliğine yönelik 24 maddeden oluşan birinci boyutun güvenirlik katsayısı 0,961, EBA'nın uygulanabilirliğine yönelik 6 maddeden oluşan ikinci boyutun güvenirlik katsayısı $0,712^{\prime}$ dir. Ölçeğin genel güvenirlik katsayısı ise 0,950'dir. Bu çalışmada ise ölçeğin genel güvenirlik katsayısı 0,933 olarak hesaplanmıştır.

Verilerin toplanmasında çevrimiçi sosyal medya platformları (Whatsapp, Facebook, Telegram) kullanılmıştır. Çevrimiçi form olarak düzenlenen ölçeğin bağlantı linki bahsi geçen platformlardaki DKAB öğretmenlerinden oluşan gruplarda paylaşılarak ölçek katılımcılara ulaştırılmıştır. Çalışmada kullanılan ölçek için Sivas Cumhuriyet Üniversitesi Hukuk Müşavirliği'nden 02.04.2021 tarih ve E60263016-050.06.04-29071 sayılı etik kuru onayı alınmıştır.

Verilerin analizinde SPSS 25.0 paket programı kullanılmıştır. Araştırmaya katılan DKAB öğretmenlerinin EBA'ya ilişkin tutumları hem her bir madde açısından, hem de genel olarak incelenmiştir. Verilerin normal dağılıp dağılmadığını belirlemek için "Kolmogorov Smirnov" normallik testi kullanılmıştır. Testin sonuçları Tablo 2'de belirtilmiştir.

Tablo 2. DKAB Öğretmenlerinin EBA'ya İlişkin Tutumlarının Normallik Testi Sonuçları

\begin{tabular}{|c|c|c|c|}
\hline & & Statistic & Std. Error \\
\hline Mean & & 3,5051 & 0,03060 \\
\hline \multirow{2}{*}{ 95\% Confidence Interval for Mean } & Lower Bound & 3,4449 & \\
\hline & Upper Bound & 3,5653 & \\
\hline $5 \%$ Trimmed Mean & & 3,5136 & \\
\hline Median & & 3,5333 & \\
\hline Variance & & 0,295 & \\
\hline Std. Deviation & & 0,54314 & \\
\hline Minimum & & 1,53 & \\
\hline Maximum & & 4,93 & \\
\hline Range & & 3,40 & \\
\hline Interquartile Range & & 0,70 & \\
\hline Skewness & & $-0,359$ & 0,137 \\
\hline Kurtosis & & 0,890 & 0,274 \\
\hline
\end{tabular}

Bu teste göre çarpıklık (Skewness) değeri -,359, basıklık (Kurtosis) değeri ,890 olarak bulunmuştur. Bu değerler -1.5 ile +1.5 arasında olduğu için verilerin normal dağılım gösterdiği kabul edilmiştir. ${ }^{18}$

Puan ortalamalarının karşılaştııılmasında puan aralıkları dikkate alınmıştır. Ölçekten alınan puan ortalamaları 1.00-2.32 arası ise düşük, 2.33-3.66 arası ise orta, 3,67-4.00 arası ise yüksek olarak değerlendirilmiştir. Ölçekte yer alan her bir yeterlik boyutunda, ortalama puanların bağımsız değişkenlerle ilişkisini belirlemek için bağımsız değişkenin niteliğine göre farklı teknikler kullanılmıştır. İki alt kategoriye ayrılan bağımsız değişkenler için "Bağımsız Örneklemler T-Testi" (Independent Samples T-Test), ikiden fazla kategoriye ayrılan bağımsız değişkenler için "Tek Yönlü Varyans Analizi" (One Way ANOVA) testi kullanılmıştır. Anova sonuçlarına göre gruplar arasında manidar bir farklılaşma söz konusu ise, bu farklılı̆̆ın kaynağını belirlemek için Post-Hoc çoklu karşılaştırma testleri kullanılmıştır. Levene testi sonuçlarına göre varyansı homojen olan gruplarda LSD ${ }^{19}$, varyansı homojen olmayan gruplarda Tamhane's T2 testi kullanılmıştır. Araştırmada gerçekleştirilen tüm analizlerde manidarlık düzeyi 0,05 olarak kabul edilmiştir.

Gruplardaki örneklem sayılarının 10'dan fazla olması ve birbirine yakın olması varyans analizlerinin güvenirliği açısından tercih edilen bir durumdur. Ancak elde olmayan nedenlerden

\footnotetext{
${ }^{17}$ Burcu Uğurlu - Gülden Gürsoy, “Eğitim Bilişim Ağı Tutum Ölçeği Geliştirme Çalışması”, Eğitim Teknolojisi Kuram ve Uygulama 8/2 (2018), 35-66.

${ }^{18}$ Barabara G. Tabachnick - Linda S. Fidell, Using Multivarite Statistics (Boston: Pearson, 2013), 79.

${ }^{19}$ Uygulama kolaylığı ve daha küçük ortalama farkların önemli bulunması ihtimali yüksek olduğu için bu test kullanılmıştır. Serpil Ergün Bülbül, “Çoklu Karşılaştırma Testleri ve Bir Örnek Uygulama”, Öneri Dergisi 3/14 (2000), 97.
} 
ötürü bu şartlar sağlanamayabilir. Bu durumda mevcut verilerle fakat farklı formüllerle testin yapılması gerekir. SPSS'le yapılan analizlerde ise gruplardaki veri sayısının aynı ya da farklı olmasının bir önemi yoktur. ${ }^{20} \mathrm{Bu}$ çalışmada, verilerin toplanması çevrimiçi sosyal medya platformları aracılığıyla yapıldığı için, gruplar arasında öngörülemeyen orantısızlıklar oluşmuştur. Elde edilen veriler SPSS yordamıla analiz edilmiştir.

\subsection{Araştırmanın Sinırlılikları}

DKAB öğretmenlerinin EBA'ya ilişkin tutumlarının incelendiği bu çalışmanın bulguları, çalışmada kullanılan veri toplama aracıyla, bu araçla elde edilen verilerle ve bu aracın uygulandığı örneklemle sinurlidir.

\section{Bulgular ve Yorumlar}

\subsection{DKAB Öğretmenlerinin EBA'ya İlişkin Tutumlarının Düzeyine Dair Betimsel Bulgular}

DKAB öğretmenlerinin EBA'ya yönelik tutumlarının düzeyini belirlemek için yapılan analiz sonuçlarına göre elde edilen bulgular Tablo 3'te belirtilmiştir.

Tablo 3. DKAB Öğretmenlerinin EBA'ya İlişkin Tutumlarının Düzeyi

\begin{tabular}{|c|c|c|c|c|}
\hline Boyut & Madde & $x$ & Ss & $\begin{array}{l}\text { Tutum } \\
\text { Düzeyi }\end{array}$ \\
\hline \multirow{16}{*}{ 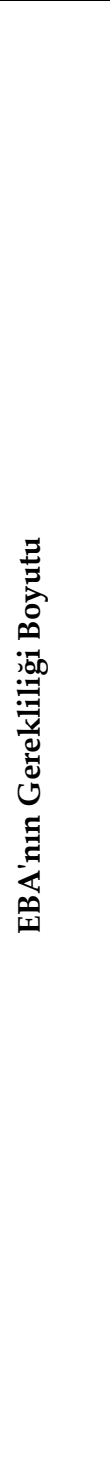 } & $\begin{array}{l}\text { EBA'nın, öğrencilerin derse yönelik ilgisini artırıyor olmasını } \\
\text { önemsiyorum. }\end{array}$ & 3,44 & 1,02 & Orta \\
\hline & $\begin{array}{l}\text { EBA'nın, öğrencilerin dersi anlamalarına sağladığı katkıyı önemli } \\
\text { buluyorum. }\end{array}$ & 3,47 & 0,95 & Orta \\
\hline & $\begin{array}{l}\text { EBA'yı kullandığımda konularımı zamanında yetiştiremeyeceğim } \\
\text { düşüncesi beni ENDİŞELENDİRIYYOR. }\end{array}$ & 3,63 & 1,03 & Orta \\
\hline & $\begin{array}{l}\text { EBA'nın, öğrencilerin değişik fikirler üretmesine sağladığı katkı } \\
\text { keyif vericidir. }\end{array}$ & 3,08 & 0,98 & Orta \\
\hline & $\begin{array}{l}\text { EBA'nın, öğrencilere ders saatleri dışında tekrar imkânı } \\
\text { sağlamasını önemli buluyorum. }\end{array}$ & 3,96 & 0,88 & Yüksek \\
\hline & $\begin{array}{l}\text { EBA, öğrencilerin konuyu anlamalarına önemli bir katkı } \\
\text { SAĞLAMAZ. }\end{array}$ & 3,75 & 0,89 & Yüksek \\
\hline & $\begin{array}{l}\text { EBA'nın, öğrencilerin konuyu kendi hızlarına göre öğrenmelerine } \\
\text { sağladığı desteği önemsiyorum. }\end{array}$ & 3,49 & 0,88 & Orta \\
\hline & $\begin{array}{l}\text { EBA'nın, öğrencilerin ilginç bilgiler öğrenmelerine imkân sağlıyor } \\
\text { olması keyif vericidir. }\end{array}$ & 3,50 & 0,92 & Orta \\
\hline & $\begin{array}{l}\text { EBA'nın, dersleri öğrenciler açısından daha eğlenceli hale } \\
\text { getireceğini umuyorum. }\end{array}$ & 3,49 & 0,88 & Orta \\
\hline & $\begin{array}{l}\text { EBA'da yer alan materyallerin ders sunumuma sağladığı desteği } \\
\text { önemli buluyorum. }\end{array}$ & 3,51 & 0,97 & Orta \\
\hline & $\begin{array}{l}\text { EBA platformu ile kalabalık sınıflarda verim alamamaktan } \\
\text { ENDİŞE duyarım. }\end{array}$ & 2,91 & 1,08 & Orta \\
\hline & $\begin{array}{l}\text { EBA'nın, derslerimin daha planlı ilerlemesine olan katkısı keyif } \\
\text { vericidir. }\end{array}$ & 3,29 & 0,93 & Orta \\
\hline & $\begin{array}{l}\text { EBA DERS'teki ödevleri, öğrencilere göndermenin iş yükümü (ek } \\
\text { ders notu oluşturma ve fotokopi çekme gibi konularda) azaltıyor } \\
\text { olması keyif vericidir. }\end{array}$ & 3,63 & 1,01 & Orta \\
\hline & $\begin{array}{l}\text { EBA'nın, materyal hazırlama konusunda beni pasifleştirmesinden } \\
\text { ENDİŞE duyuyorum. }\end{array}$ & 3,73 & 0,85 & Yüksek \\
\hline & $\begin{array}{l}\text { Ders sırasında, EBA'da yer alan etkinlikleri uygulamanın, zaman } \\
\text { yönetimi açısından sağladığı avantajı önemsiyorum. }\end{array}$ & 3,57 & 0,82 & Orta \\
\hline & $\begin{array}{l}\text { EBA'daki zengin içeriğin dersime çeşitlilik katması hoşuma } \\
\text { gidiyor. }\end{array}$ & 3,47 & 0,98 & Orta \\
\hline
\end{tabular}

\footnotetext{
${ }^{20}$ Karagöz, SPSS ve AMOS 23 Uygulamah İstatistiksel Analizler, 412.
} 


\begin{tabular}{|c|c|c|c|c|}
\hline & EBA platformu, öğretim açısından iyi bir tamamlayıcıdır. & 3,64 & 0,80 & Orta \\
\hline & $\begin{array}{l}\text { EBA kullanmanin, öğretmen olarak beni ikinci plana iteceği } \\
\text { düşüncesi beni ENDİŞELENDİRIYYOR. }\end{array}$ & 4,01 & 0,81 & Yüksek \\
\hline & $\begin{array}{l}\text { EBA'nın, çeşitli öğretim yöntemlerini kullanmama imkan } \\
\text { sağlamasından hoşnutum. }\end{array}$ & 3,57 & 0,84 & Orta \\
\hline & $\begin{array}{l}\text { Sinıf ortamında yapılamayacak etkinlikleri, EBA'yı kullanarak } \\
\text { yapabilmek güzeldir. }\end{array}$ & 3,51 & 0,96 & Orta \\
\hline & $\begin{array}{l}\text { EBA'nın, derse materyal getirme ihtiyacını önemli ölçüde } \\
\text { karşılaması hoşuma gidiyor. }\end{array}$ & 3,44 & 0,93 & Orta \\
\hline & EBA'yı kullanırken teknik aksaklıklar yaşamaktan KORKARIM. & 2,63 & 1,11 & Orta \\
\hline & $\begin{array}{l}\text { EBA'yı kullanmanın, derste yazmaya harcadığım zamanı } \\
\text { azaltmasından hoşnutum. }\end{array}$ & 3,47 & 1,00 & Orta \\
\hline & EBA ile ilgili haberler dikkatimi ÇEKMEZ. & 4,00 & 0,79 & Yüksek \\
\hline$\overline{\text { EBA }}$ & Gerekliliği Boyutu Ortalaması & 3,51 & 0,54 & Orta \\
\hline$\Xi$ & Öğretmenlerin EBA'yı kullanmaları gerektiğine inanıyorum. & 4,03 & 0,84 & Yüksek \\
\hline$\sum_{i 00}^{0}$ & EBA'nın, beni daha etkin bir öğretmen yaptığını hissediyorum. & 3,22 & 0,97 & Orta \\
\hline$\frac{\mathfrak{g}}{3}$ & $\begin{array}{l}\text { EBA'dan ilginç bilgilere ulaşmak, bu platforma yönelik ilgimi } \\
\text { artırır. }\end{array}$ & 3,60 & 0,89 & Orta \\
\hline 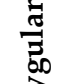 & $\begin{array}{l}\text { EBA içeriğinin ders kitabına göre daha kapsamlı olması hoşuma } \\
\text { gidiyor. }\end{array}$ & 3,43 & 0,96 & Orta \\
\hline$\underset{5}{\Xi}$ & $\begin{array}{l}\text { EBA'daki içeriklerin öğrencilerin hazır bulunuşluklarını dikkate } \\
\text { almamış olması beni RAHATSIZ ediyor. }\end{array}$ & 3,11 & 0,95 & Orta \\
\hline 迎 & $\begin{array}{l}\text { EBA'nın, öğretmenlerin kaynak ihtiyacını karşılama noktasında } \\
\text { sağladığ1 katkı güzeldir. }\end{array}$ & 3,59 & 0,97 & Orta \\
\hline EBA & Uygulanabilirliği Boyutu Ortalaması & 3,50 & 0,66 & Orta \\
\hline Ger & talama & 3,51 & 0,54 & Orta \\
\hline
\end{tabular}

Tablo 3'e göre araştırmaya katılan DKAB öğretmenlerinin EBA'ya ilişkin tutmlarının puan ortalaması 3.51'dir. Bu sonuca göre DKAB öğretmenlerinin EBA'ya ilişkin tutumlarının orta düzeyde ve pozitif yönde olduğu anlaşılmaktadır. Ölçeğin alt boyutlarına bakıldığında, EBA'nın Gerekliliği alt boyutunun puan ortalaması 3.51, EBA'nın Uygulanabilirliği alt boyutunun puan ortalaması 3.50'dir. Her iki alt boyutta da öğretmenlerin tutumlarının pozitif yönde ve orta düzeyde olduğu görülmektedir. Ölçekte yer alan maddelere göre ortalamalar incelendiğinde, öğretmenlerin tutum düzeyleri EBA'nın gerekliliğine yönelik 5 maddede yüksek, 19 maddede orta düzeyde; EBA'nın uygulanabilirliğine yönelik 1 maddede yüksek, 5 maddede ise orta düzeydedir. Konuyla ilgili farklı zaman ve örneklemlerde yapılan araştırmalarda da benzer sonuçlar ortaya çıkmıştır. ${ }^{21}$

2.2. DKAB Öğretmenlerinin EBA'ya İlişkin Tutumlarının Bağımsız Değişkenlerle İlişkisine Dair Bulgular

DKAB öğretmenlerinin EBA'ya ilişkin tutumlarında, cinsiyete göre manidar bir farklılaşma olup olmadığını belirlemek için bağımsız örneklem $t$ testi yapılmıştır. Testin sonuçları Tablo 4 'te belirtilmiştir.

Tablo 4. DKAB Öğretmenlerinin EBA'ya İlişkin Tutumlarının Cinsiyete Göre T Testi Sonuçları

${ }^{21}$ Varışoğlu, “Öğretmenlerin Eğitim Bilişim Ağı (EBA) Tutumlarının İncelenmesi”, 3514; Bayyiğit Teker, Öğretmenlerin Teknolojik Pedagojik Alan Bilgisi (TPAB) Yeterlilikleri İle Ĕ̆̈itim Bilişim A ̆̆g (EBA) Kullanımına Yönelik Tutumları Arasındaki İlişki, 57; Aztekin, Öğretmenlerin Ĕ̆̈itim Bilişim Ağı'na Yönelik Farkındalık Düzeyleri Ve Tutumları Arasındaki İlişkinin İncelenmesi, 74-75; Şireci, Öğretmenlerin EBA Tutumlarının Farklı Değişkenler Açısından İncelenmesi, 45. 
BİNGÖL ÜNIVERSITESİ İLAHIYAT FAKÜLTESİ DERGISİ-SAYI-18 ARALIK

\begin{tabular}{|c|c|c|c|c|c|c|c|}
\hline Boyut & Cinsiyet & $\mathbf{N}$ & $x$ & Ss & $\mathbf{t}$ & sd & p \\
\hline \multirow[t]{2}{*}{ Uygulanabilirlik } & Kadın & 172 & 3,47 & 0,68 & $-0,764$ & 313 & 0,446 \\
\hline & Erkek & 143 & 3,53 & 0,64 & & & \\
\hline \multirow[t]{2}{*}{ Gereklilik } & Kadın & 172 & 3,48 & 0,56 & $-0,858$ & 313 & 0,392 \\
\hline & Erkek & 143 & 3,54 & 0,52 & & & \\
\hline \multirow[t]{2}{*}{ Genel } & Kadın & 172 & 3,48 & 0,56 & $-0,869$ & 313 & 0,385 \\
\hline & Erkek & 143 & 3,53 & 0,52 & & & \\
\hline
\end{tabular}

Tabloya göre araştırmaya katılan DKAB öğretmenlerinin EBA'ya ilişkin tutumlarında, cinsiyete göre istatistiksel olarak anlamlı bir farklılaşma yoktur [ $\left.\mathrm{t}_{(313)}=0.869 ; \mathrm{p}=0.385\right]$. Bu sonuç, DKAB öğretmenlerinin EBA'ya ilişkin tutumlarında, cinsiyet değişkeninin etkisinin olmadığı anlamına gelmektedir. Sonuçlara göre ölçeğin alt boyutlarında da cinsiyet değişkenin anlamlı bir etkisinin olmadığı görülmektedir. Bu sonuç, konuyla ilgili olarak farklı örneklemlerde yapılan araştırmalarda ulaşılan sonuçlarla paralellik göstermektedir. ${ }^{22}$

DKAB öğretmenlerinin EBA'ya ilişkin tutumlarında yaş değişkenine göre manidar bir farklılaşma olup olmadığını belirlemek için tek yönlü varyans analizi (ANOVA) yapılmıştır. Analiz sonuçları Tablo 5'te belirtilmiştir.

Tablo 5. DKAB öğretmenlerinin EBA'ya İlişkin Tutumlarının Yaşa Göre ANOVA Testi Sonuçları

\begin{tabular}{|c|c|c|c|c|c|c|c|c|c|c|}
\hline Boyut & Yaş & $\mathbf{N}$ & $x$ & Ss & $\begin{array}{l}\text { Varyans } \\
\text { Kaynağ1 }\end{array}$ & KT & sd & KO & $\mathbf{F}$ & p \\
\hline \multirow[t]{5}{*}{ Uygulanabilirlik } & $21-30$ & 100 & 3,53 & 0,65 & $\begin{array}{l}\text { Gruplar } \\
\text { Arası }\end{array}$ & 1,485 & 3 & 0,495 & 1,139 & 0,334 \\
\hline & $31-40$ & 129 & 3,51 & 0,64 & $\begin{array}{l}\text { Gruplar } \\
\text { İçi }\end{array}$ & 135,179 & 311 & 0,435 & & \\
\hline & $41-50$ & 61 & 3,50 & 0,71 & Toplam & 136,663 & 314 & & & \\
\hline & 51 ve üzeri & 25 & 3,27 & 0,69 & & & & & & \\
\hline & Toplam & 315 & 3,50 & 0,66 & & & & & & \\
\hline \multirow[t]{5}{*}{ Gereklilik } & $21-30$ & 100 & 3,47 & 0,57 & $\begin{array}{l}\text { Gruplar } \\
\text { Arası }\end{array}$ & 1,360 & 3 & 0,453 & 1,556 & 0,200 \\
\hline & $31-40$ & 129 & 3,54 & 0,50 & $\begin{array}{l}\text { Gruplar } \\
\text { İçi }\end{array}$ & 90,572 & 311 & 0,291 & & \\
\hline & $41-50$ & 61 & 3,57 & 0,55 & Toplam & 91,932 & 314 & & & \\
\hline & 51 ve üzeri & 25 & 3,33 & 0,59 & & & & & & \\
\hline & Toplam & 315 & 3,51 & 0,54 & & & & & & \\
\hline \multirow[t]{5}{*}{ Genel } & $21-30$ & 100 & 3,48 & 0,56 & $\begin{array}{l}\text { Gruplar } \\
\text { Arası }\end{array}$ & 1,250 & 3 & 0,417 & 1,418 & 0,238 \\
\hline & $31-40$ & 129 & 3,54 & 0,50 & $\begin{array}{l}\text { Gruplar } \\
\text { İçi }\end{array}$ & 91,382 & 311 & 0,294 & & \\
\hline & $41-50$ & 61 & 3,55 & 0,57 & Toplam & 92,632 & 314 & & & \\
\hline & 51 ve üzeri & 25 & 3,31 & 0,60 & & & & & & \\
\hline & Toplam & 315 & 3,51 & 0,54 & & & & & & \\
\hline
\end{tabular}

Tabloya göre araştırmaya katılan DKAB öğretmenlerinin EBA'ya ilişkin tutumlarında yaş değişkenine göre istatistiksel olarak anlamlı bir farklılaşma olmamıştır $\left[\mathrm{F}_{(3,311)}=1.418 ; \mathrm{p}=0.238\right]$. $\mathrm{Bu}$

22 Varışoğlu, “Öğretmenlerin Eğitim Bilişim Ağı (EBA) Tutumlarının İncelenmesi”, 3519; Bayyiğit Teker, Öğretmenlerin Teknolojik Pedagojik Alan Bilgisi (TPAB) Yeterlilikleri İle Eğitim Bilişim Ağı (EBA) Kullanımına Yönelik Tutumlarn Arasındaki İlişki, 59; Aztekin, Öğretmenlerin Eğitim Bilişim Ağı'na Yönelik Farkındalık Düzeyleri Ve Tutumları Arasındaki İlişkinin İncelenmesi, 75; Şireci, Öğretmenlerin EBA Tutumlarının Farklı Değişkenler Açısından İncelenmesi, 46. 
sonuca göre DKAB öğretmenlerinin EBA'ya ilişkin tutumlarında, yaş değişkeninin etkisinin olmadığ anlaşılmaktadır. Ölçeğin alt boyutları için de aynı durum söz konusu olup, EBA'nun uygulanabilirliği ve gerekliliği konusunda, farklı yaş grubundaki DKAB öğretmenlerinin benzer tutumlara sahip olduğu anlaşılmaktadır. Varışoğlu tarafından yapılan araştırmada da benzer sonuçlara ulaşılmıştır. ${ }^{23}$ Aztekin tarafından yapılan araştırmada, uygulanabilirlik boyutunda anlamlı bir farklılık oluşmazken, gereklilik boyunda 41-50 yaş grubundaki öğretmenlerin ortalaması düşük çıkmıştır. ${ }^{24}$

DKAB öğretmenlerinin EBA'ya ilişkin tutumlarında hizmet yılı değişkenine göre anlamlı bir farklılaşma olup olmadığını belirlemek amacıyla tek yönlü varyans analizi yapılmıştır. Analiz sonuçları Tablo 6 'da belirtilmiştir.

Tablo 6. DKAB Öğretmenlerinin EBA’ya İlişkin Tutumlarının Hizmet Yılına Göre ANOVA Testi Sonuçları

\begin{tabular}{|c|c|c|c|c|c|c|c|c|c|c|}
\hline Boyut & $\begin{array}{c}\text { Hizmet } \\
\text { Yilı }\end{array}$ & $\mathbf{N}$ & $x$ & Ss & $\begin{array}{l}\text { Varyans } \\
\text { Kaynağ1 }\end{array}$ & KT & sd & KO & $\mathbf{F}$ & $\mathrm{p}$ \\
\hline \multirow[t]{7}{*}{ Uygulanabilirlik } & $1-5$ & 96 & 3,58 & 0,62 & $\begin{array}{l}\text { Gruplar } \\
\text { Aras1 }\end{array}$ & 4,563 & 5 & 0,913 & 2,135 & 0,061 \\
\hline & $6-10$ & 102 & 3,45 & 0,65 & Gruplar İçi & 132,100 & 309 & 0,428 & & \\
\hline & $11-15$ & 56 & 3,52 & 0,68 & Toplam & 136,663 & 314 & & & \\
\hline & $16-20$ & 26 & 3,69 & 0,60 & & & & & & \\
\hline & $21-25$ & 12 & 3,15 & 0,82 & & & & & & \\
\hline & $\begin{array}{l}26 \text { ve } \\
\text { üzeri }\end{array}$ & 23 & 3,26 & 0,71 & & & & & & \\
\hline & Toplam & 315 & 3,50 & 0,66 & & & & & & \\
\hline \multirow[t]{7}{*}{ Gereklilik } & $1-5$ & 96 & 3,52 & 0,59 & $\begin{array}{l}\text { Gruplar } \\
\text { Arası }\end{array}$ & 3,112 & 5 & 0,622 & 2,165 & 0,058 \\
\hline & $6-10$ & 102 & 3,48 & 0,48 & Gruplar İçi & 88,820 & 309 & 0,287 & & \\
\hline & $11-15$ & 56 & 3,59 & 0,55 & Toplam & 91,932 & 314 & & & \\
\hline & $16-20$ & 26 & 3,68 & 0,47 & & & & & & \\
\hline & $21-25$ & 12 & 3,19 & 0,47 & & & & & & \\
\hline & $\begin{array}{l}26 \text { ve } \\
\text { üzeri }\end{array}$ & 23 & 3,34 & 0,62 & & & & & & \\
\hline & Toplam & 315 & 3,51 & 0,54 & & & & & & \\
\hline \multirow[t]{7}{*}{ Genel } & $1-5$ & 96 & 3,53 & 0,57 & $\begin{array}{l}\text { Gruplar } \\
\text { Arası }\end{array}$ & 3,261 & 5 & 0,652 & 2,255 & 0,049 \\
\hline & $6-10$ & 102 & 3,47 & 0,49 & Gruplar İçi & 89,371 & 309 & 0,289 & & \\
\hline & $11-15$ & 56 & 3,58 & 0,55 & Toplam & 92,632 & 314 & & & \\
\hline & $16-20$ & 26 & 3,68 & 0,48 & & & & & & \\
\hline & $21-25$ & 12 & 3,18 & 0,53 & & & & & & \\
\hline & $\begin{array}{l}26 \text { ve } \\
\text { üzeri }\end{array}$ & 23 & 3,33 & 0,63 & & & & & & \\
\hline & Toplam & 315 & 3,51 & 0,54 & & & & & & \\
\hline
\end{tabular}

Tabloya göre araştırmaya katılan DKAB öğretmenlerinin EBA'ya ilişkin tutumları ile hizmet süreleri arasında istatistiksel olarak anlamlı bir ilişki söz konusudur $\left[\mathrm{F}_{(5,309)}=2.255 ; \mathrm{p}=0.049\right]$. $\mathrm{Bu}$ ilişkinin hangi gruplar arasında olduğunu belirlemek amacıyla post-hoc analizi yapılmıştır. Levene's testi sonuçlarına göre hizmet yılı grupları homojen dağılım gösterdiği için ( $L F=0,553 ; \mathrm{p}=0.736)$ posthoc LSD testi tercih edilmiştir. LSD sonuçlarına göre 1-5, 11-15 ve 16-20 yll hizmet süresi olan öğretmenlerin 21-25 yıl hizmeti olanlara göre; 16-20 yıl hizmeti olan öğretmenlerin 26 yıl ve üzeri

23 Varışoğlu, “Öğretmenlerin Eğitim Bilişim Ağı (EBA) Tutumlarının İncelenmesi”, 3519.

${ }^{24}$ Aztekin, Öğretmenlerin Eğitim Bilişim Ağgı'na Yönelik Farkındalık Düzeyleri Ve Tutumları Arasındaki İlişkinin İncelenmesi, 76. 
hizmeti olanlara göre EBA'ya ilişkin tutumlarının daha yüksek ortalamaya sahip olduğu tespit edilmiştir. Bu sonuçlara göre hizmet süresi düşük olan, dolayısıyla meslekte yeni olan DKAB öğretmenlerinin EBA'ya ilişkin tutumlarının daha olumlu olduğu söylenebilir. DKAB öğretmenlerinin EBA'ya ilişkin tutumları ile hizmet süreleri arasında ölçeğin geneli açısından ortaya çıkan bu ilişki, ölçeğin alt boyutları için söz konusu olmamıştır. Varışoğlu ${ }^{25}$ ve Bayyiğit Teker ${ }^{26}$ tarafından yapılan araştırmalarda, öğretmenlerin EBA'ya ilişkin tutumları ile hizmet süreleri arasında anlamlı bir ilişki bulunamamıştır. Aztekin'in araştırmasında, 21 yıl ve üzeri hizmeti olan öğretmenlerin EBA'nın gerekliliği boyutundaki puan ortalamaları daha düşük çıkmıştır. ${ }^{27}$ Şireci'nin araştırmasında ise 26 yıl ve üzeri hizmeti olanların puan ortalaması daha yüksek çıkmıştır. ${ }^{28}$

DKAB öğretmenlerinin EBA'ya ilişkin tutumlarında çalışılan okul türüne göre anlamlı bir farklılaşma olup olmadığını belirlemek amacıyla tek yönlü varyans analizi yapılmıştır. Analiz sonuçları Tablo 7 'de belirtilmiştir.

Tablo 7. DKAB öğretmenlerinin EBA'ya İlişkin Tutumlarının Çalışılan Okul Türüne Göre ANOVA Testi Sonuçları

\begin{tabular}{|c|c|c|c|c|c|c|c|c|c|c|}
\hline Boyut & $\begin{array}{c}\text { Çalışılan } \\
\text { Okul } \\
\text { Türüu }\end{array}$ & $\mathbf{N}$ & $x$ & Ss & $\begin{array}{l}\text { Varyans } \\
\text { Kaynağı }\end{array}$ & KT & sd & KO & $\mathbf{F}$ & $\mathrm{p}$ \\
\hline \multirow[t]{4}{*}{ Uygulanabilirlik } & İlkokul & 13 & 3,51 & 0,70 & $\begin{array}{l}\text { Gruplar } \\
\text { Arası }\end{array}$ & 0,015 & 2 & 0,007 & 0,017 & 0,984 \\
\hline & Ortaokul & 239 & 3,49 & 0,64 & Gruplar İçi & 136,649 & 312 & 0,438 & & \\
\hline & Lise & 63 & 3,51 & 0,72 & Toplam & 136,663 & 314 & & & \\
\hline & Toplam & 315 & 3,50 & 0,66 & & & & & & \\
\hline \multirow[t]{4}{*}{ Gereklilik } & İlkokul & 13 & 3,57 & 0,50 & $\begin{array}{l}\text { Gruplar } \\
\text { Arası }\end{array}$ & 0,196 & 2 & 0,098 & 0,333 & 0,717 \\
\hline & Ortaokul & 239 & 3,52 & 0,53 & Gruplar İçi & 91,736 & 312 & 0,294 & & \\
\hline & Lise & 63 & 3,46 & 0,60 & Toplam & 91,932 & 314 & & & \\
\hline & Toplam & 315 & 3,51 & 0,54 & & & & & & \\
\hline \multirow[t]{4}{*}{ Genel } & İlkokul & 13 & 3,56 & 0,51 & $\begin{array}{l}\text { Gruplar } \\
\text { Arası }\end{array}$ & 0,118 & 2 & 0,059 & 0,199 & 0,819 \\
\hline & Ortaokul & 239 & 3,51 & 0,53 & Gruplar İçi & 92,514 & 312 & 0,297 & & \\
\hline & Lise & 63 & 3,47 & 0,61 & Toplam & 92,632 & 314 & & & \\
\hline & Toplam & 315 & 3,51 & 0,54 & & & & & & \\
\hline
\end{tabular}

Tabloya göre araştırmaya katılan DKAB öğretmenlerinin EBA'ya ilişkin tutumlarında, çalışılan okul türüne göre istatistiksel olarak anlamlı bir farklılaşma olmamıştır $\left[\mathrm{F}_{(2,312)}=0.199 ; \mathrm{p}=0.819\right]$. $\mathrm{Bu}$ sonuca göre DKAB öğretmenlerinin ilkokul, ortaokul ya da lisede görev yapıyor olmalarının, onların EBA'ya ilişkin tutumlarını etkilemediği anlaşılmaktadır. Ölçeğin alt boyutları içinde aynı durum söz konusudur.

DKAB öğretmenlerinin EBA'ya ilişkin tutumlarında mezun olunan yükseköğretim programına göre anlamlı bir farklılaşma olup olmadığını belirlemek amacıyla tek yönlü varyans analizi yapılmıştır. Analiz sonuçları Tablo 8 'de belirtilmiştir.

Tablo 8. DKAB öğretmenlerinin EBA'ya İlişkin Tutumlarının Mezun olunan Yükseköğretim Programına Göre ANOVA Testi Sonuçları

\footnotetext{
${ }^{25}$ Varışoğlu, “Öğretmenlerin Eğitim Bilişim Ağı (EBA) Tutumlarının İncelenmesi”, 3519.

${ }^{26}$ Bayyiğit Teker, Öğretmenlerin Teknolojik Pedagojik Alan Bilgisi (TPAB) Yeterlilikleri İle Ĕ̆gitim Bilişim A ̆ğ (EBA) Kullanımına Yönelik Tutumları Arasındaki İlişki, 60.

${ }_{27}$ Aztekin, Öğretmenlerin Ĕ̆itim Bilişim Ă̆̊ı'na Yönelik Farkındalık Düzeyleri Ve Tutumları Arasındaki İlişkinin İncelenmesi, 78.

${ }^{28}$ Şireci, Ö̆̆retmenlerin EBA Tutumlarımın Farklı Değişsenler Açısından İncelenmesi, 49.
} 


\begin{tabular}{|c|c|c|c|c|c|c|c|c|c|c|}
\hline \multicolumn{9}{|c|}{ BİNGÖL ÜNIVERSİTESİ İLAHIYYAT FAKÜLTESİ DERGİSİ-SAYI-18 } & \multicolumn{2}{|c|}{$\begin{array}{c}\text { ARALIK } \\
2021\end{array}$} \\
\hline Boyut & $\begin{array}{c}\text { Mezun Olunan } \\
\text { Yükseköğretim } \\
\text { Programı }\end{array}$ & $\mathrm{N}$ & $x$ & Ss & $\begin{array}{l}\text { Varyans } \\
\text { Kaynağ1 }\end{array}$ & $\mathrm{KT}$ & $\mathrm{sd}$ & $\mathrm{KO}$ & $\mathrm{F}$ & $\mathrm{p}$ \\
\hline \multirow[t]{7}{*}{ Uygulanabilirlik } & Yüksek İslam & 2 & 3,08 & 1,30 & Gruplar & 2,998 & 4 & 0,74 & 1,73 & 0,14 \\
\hline & Enstitüsü & & & & Arası & & & 9 & 8 & 1 \\
\hline & $\begin{array}{l}\text { Eski İlahiyat } \\
\text { Fakültesi }\end{array}$ & 168 & 3,47 & 0,68 & $\begin{array}{l}\text { Gruplar } \\
\text { İçi }\end{array}$ & 133,666 & $\begin{array}{c}31 \\
0 \\
\end{array}$ & $\begin{array}{c}0,43 \\
1 \\
\end{array}$ & & \\
\hline & $\begin{array}{l}\text { İlahiyat } \\
\text { Fakültesi } \\
\text { DKAB Bölümü }\end{array}$ & 72 & 3,45 & 0,65 & Toplam & 136,663 & $\begin{array}{c}31 \\
4\end{array}$ & & & \\
\hline & $\begin{array}{l}\text { Ĕ̆itim } \\
\text { Fakültesi } \\
\text { DKAB Bölümü }\end{array}$ & 55 & 3,52 & 0,58 & & & & & & \\
\hline & $\begin{array}{l}\text { Yeni } \\
\text { İlahiyat/İslami } \\
\text { İlimler } \\
\text { Fakültesi }\end{array}$ & 18 & 3,86 & 0,60 & & & & & & \\
\hline & Toplam & 315 & 3,50 & 0,66 & & & & & & \\
\hline \multirow[t]{7}{*}{ Gereklilik } & Yüksek İslam & 2 & 3,31 & 0,97 & Gruplar & 1,266 & 4 & 0,31 & 1,08 & 0,36 \\
\hline & Enstitüsü & & & & Aras1 & & & 6 & 2 & 5 \\
\hline & $\begin{array}{l}\text { Eski İlahiyat } \\
\text { Fakültesi }\end{array}$ & 168 & 3,52 & 0,54 & $\begin{array}{l}\text { Gruplar } \\
\text { İçi }\end{array}$ & 90,666 & $\begin{array}{c}31 \\
0 \\
\end{array}$ & $\begin{array}{c}0,29 \\
2 \\
\end{array}$ & & \\
\hline & $\begin{array}{l}\text { İlahiyat } \\
\text { Fakültesi } \\
\text { DKAB Bölümü } \\
\end{array}$ & 72 & 3,48 & 0,56 & Toplam & 91,932 & $\begin{array}{c}31 \\
4\end{array}$ & & & \\
\hline & $\begin{array}{l}\text { Eğitim } \\
\text { Fakültesi } \\
\text { DKAB Bölümü }\end{array}$ & 55 & 3,45 & 0,48 & & & & & & \\
\hline & $\begin{array}{l}\text { Yeni } \\
\text { İlahiyat/İslami } \\
\text { İlimler } \\
\text { Fakültesi }\end{array}$ & 18 & 3,73 & 0,59 & & & & & & \\
\hline & Toplam & 315 & 3,51 & 0,54 & & & & & & \\
\hline \multirow[t]{7}{*}{ Genel } & Yüksek İslam & 2 & 3,27 & 1,04 & Gruplar & 1,442 & 4 & 0,36 & 1,22 & 0,30 \\
\hline & Enstitüsü & & & & Arası & & & 1 & 6 & 0 \\
\hline & $\begin{array}{l}\text { Eski İlahiyat } \\
\text { Fakültesi }\end{array}$ & 168 & 3,51 & 0,55 & $\begin{array}{l}\text { Gruplar } \\
\text { İçi }\end{array}$ & 91,190 & $\begin{array}{c}31 \\
0 \\
\end{array}$ & $\begin{array}{c}0,29 \\
4 \\
\end{array}$ & & \\
\hline & $\begin{array}{l}\text { İlahiyat } \\
\text { Fakültesi } \\
\text { DKAB Bölümü }\end{array}$ & 72 & 3,47 & 0,54 & Toplam & 92,632 & $\begin{array}{c}31 \\
4\end{array}$ & & & \\
\hline & $\begin{array}{l}\text { Ĕ̆itim } \\
\text { Fakültesi } \\
\text { DKAB Bölümü }\end{array}$ & 55 & 3,46 & 0,48 & & & & & & \\
\hline & $\begin{array}{l}\text { Yeni } \\
\text { İlahiyat/İslami } \\
\text { İlimler } \\
\text { Fakültesi }\end{array}$ & 18 & 3,76 & 0,57 & & & & & & \\
\hline & Toplam & 315 & 3,51 & 0,54 & & & & & & \\
\hline
\end{tabular}


Tabloya göre araştırmaya katılan DKAB öğretmenlerinin EBA'ya ilişkin tutumlarında, mezun olunan yükseköğretim programına göre istatistiksel olarak anlamlı bir farklılaşma olmamıştır $\left[\mathrm{F}_{4_{4}}\right.$ 310)=1.226; p=0.300]. Bu sonuca göre DKAB öğretmenlerinin EBA'ya ilişkin tutumlarında, hem ölçeğin geneli açısından hem de ölçeğin alt boyutları açısından, öğretmenlerin mezun oldukları yükseköğretim programının etkisinin olmadığı anlaşılmaktadır.

DKAB öğretmenliğine kaynaklık eden yükseköğretim programlarında tarihi süreçte çeşitli değişikler yapılmış ve farklı isimlerde farklı kurumlar ortaya çıkmıştır. ${ }^{29}$ Dolayısıyla günümüzde DKAB dersini okutan öğretmenler arasında, mezun oldukları yükseköğretim programı açısından farklılıklar vardır. Ancak bu durum DKAB öğretmenlerinin EBA'ya ilişkin tutumlarında bir farklılık oluşturmamıştır. DKAB öğretmenlerinin hizmet öncesi eğitimlerinde EBA'ya yönelik bir eğitim almamış olmalarının, dolayısıyla öğretmenlerin göreve başladıktan sonra EBA ile tanışmış olmalarının, ${ }^{30}$ bu sonuçta etkili olduğu söylenebilir.

\section{SONUÇ VE ÖNERILER}

DKAB öğretmenlerinin Eğitim Bilişm Ağı'na (EBA) ilişkin tutumlarının incelendiği bu araştırma, tarama modelinde olup, betimsel yöntemle yapılmıştır. Araştırmanın örneklemini, uygun örnekleme yöntemle seçilen 315 DKAB öğretmeni oluşturmaktadır. Araştırma verileri Uğurlu ve Gürsoy tarafından geliştirilen ${ }^{31}$ Eğitim Biliş̧im Ağı (EBA) Ölçeği vasıtasıyla toplanmıştır.

Araştırmada ulaşılan sonuçlara göre, DKAB öğretmenlerinin EBA'ya ilişkin tutumlarının orta düzeyde $(3,51)$ ve pozitif yönde olduğu tespit edilmiştir. Ölçeğin "gereklilik" ve "uygulanabilirlik" şeklinde adlandırılan alt boyutlarına göre, öğretmenlerin EBA'ya ilişkin tutumlarında farklılık oluşmamış, her iki alt boyutta da öğretmenlerin tutumlarının orta düzeyde ve pozitif yönde olduğu tespit edilmiştir. Bu sonuçlara göre, EBA'nın DKAB öğretmenleri tarafından gerekli ve uygulanabilir olarak görüldügü anlaşılmaktadır. Araştırma verilerinin toplandığı süreçte, Covid 19 salgını nedeniyle uzaktan eğitimin yapılıyor olmasının ve EBA'nın uzaktan eğitimin yapıldığı platformlardan biri olmasının, bu sonuçların ortaya çıkmasında etkili olduğu söylenebilir. Yani uzaktan eğitim sürecinin, öğretmenlerin EBA'ya ilişkin tutumlarını olumlu yönde etkilediği söylenebilir.

Araştırma sonuçlarına göre, DKAB öğretmenlerinin cinsiyet, yaş, çalışılan okul türü ve mezun olunan yükseköğretim programı özellikleri arasında anlamlı bir ilişki olmadığı ortaya çıkmıştır. Ölçeğin alt boyutları dikkate alındığında da aynı sonuca ulaşılmıştır. Yani öğretmenlerin cinsiyetinin, yaşının, çalıştıkları okul türünün ve mezun oldukları yükseköğretim programının, hem EBA'nın gerekliliği hem de EBA'nın uygulanabilirliği açısından öğretmenlerin tutumlarında etkili olmadığı anlaşılmaktadır.

Araştırma sonuçlarına göre DKAB öğretmenlerinin hizmet süreleri ile EBA'ya ilişkin tutumları arasında anlamlı bir ilişki olduğu tespit edilmiştir. Hizmet süresi düşük olan öğretmenlerin EBA'ya ilişkin tutumlarının, hizmet süresi yüksek olanlara göre daha olumlu olduğu görülmektedir. Ölçeğin alt boyutları açısından aynı sonuç ortaya çıkmamıştır. Yani DKAB öğretmenlerinin hizmet süresi ile EBA'nın gerekliliği ve uygulanabilirliği konusundaki tutumları arasında anlamlı bir ilişki olmadığı anlaşılmaktadır.

Covid 19 pandemisi, yüz yüze eğitimin yapılamayacağı durumlarda, uzaktan eğitim yapabilme imkânına sahip olmanın önemini artırmıştır. Bu bağlamda ülkemizde yüz yüze eğitimin yapılamadığı zamanlarda, Milli Eğitim Bakanlığı'na bağlı eğitim kurumlarında uzaktan eğitim yapılabilmesi için EBA platformu işlevsel hale getirilmiştir. Bu durumun, DKAB öğretmenlerinin DKAB derslerine yönelik içeriğin de yer aldığı EBA platformuna yönelik tutumlarını pozitif yönde etkilediği söylenebilir. EBA'ya yönelik bu olumlu tutumun yüz yüze eğitimin yapıldığı zamanlarda da devam etmesinin, EBA'nın öğretmenler tarafından yüz yüze eğitimi destekleyecek şekilde işlevsel olarak kullanılmasıyla ilişkili olacağı söylenebilir.

Yüz yüze eğitimde olduğu gibi uzaktan eğitimde de sürecin en önemli öğelerinden biri öğretmendir. Derslerin planlama, hazırlık, uygulama ve değerlendirme süreçlerinde öğretmenin

\footnotetext{
${ }^{29}$ Bk. Recai Doğan, “Cumhuriyet Dönemi İlahiyat Fakülteleri/Din Yükseköğretim: Tarihsel Gelişimi Problemleri ve Geleceği”, Türkiye'de Dinler Tarihinin Kurumsallaşması Sürecinde Prof. Dr. Abdurrahman Küçük, ed. Ahmet Hikmet Eroğlu (Ankara: Berikan Yayınevi, 2016), 231-250.

${ }^{30}$ Karasu, "İmam Hatip Meslek ve DİKAP Dersi Öğretmenlerinin Eğitim Bilişim Ağı (EBA) İle İlgili Görüşleri”, 939.

${ }^{31}$ Uğurlu - Gürsoy, “Eğitim Bilişim Ağı Tutum Ölçeği Geliştirme Çalışması”.
} 
oynadığı rol, uzaktan eğitim sürecinde de önemini korumaktadır. Uzaktan eğitimle yapılan DKAB dersinde dersi planlayan, işleyen ve değerlendiren öğretmendir. Dolayısıyla DKAB öğretmenlerinin uzaktan eğitim platformu olan EBA'ya yönelik tutumları, bu platform üzerinden yapılan DKAB dersinin niteliğini etkileyecektir. EBA'ya yönelik olumlu bir tutuma sahip olan DKAB öğretmeninin EBA platformu ile yaptığı dersin, daha etkili ve işlevsel olması beklenir. Çünkü EBA'ya yönelik olumlu bir tutuma sahip olan DKAB öğretmeni, EBA'nın sağladığı olanakların farkında olur ve dersin planlama, hazırlık, uygulama ve değerlendirme süreçlerinde bu olanakları daha etkili kullanabilir.

\section{Öneriler}

Bu çalışma EBA platformunun da kullanıldı̆̆ı uzaktan eğitim sürecinde yapılmıştır. Dolayısıyla DKAB öğretmenlerinin uzaktan eğitim sürecinde EBA'yı daha yoğun kullanmış olmalarının, araştırmada ulaşılan sonuçlarda etkili olduğu düşünülebilir. Bu nedenle yüz yüze eğitimin yapıldığı dönemlerde, daha geniş örneklemlerde araştırmalar yapılabilir ve ulaşılan sonuçlar karşılaştırmalı olarak yorumlanabilir.

Genelde tüm öğretmenlerin özelde DKAB öğretmenlerinin EBA'ya yönelik tutumlarını olumlu yönde artırmak için, EBA'nın sağladığı olanakları tanıtan hizmet içi eğitimler düzenlenebilir.

EBA platformunun DKAB dersi açısından sağladığı olanakları, hem platform üzerinden, hem de öğretmen ve öğrenci görüşlerine göre inceleyen yeni çalışmalar yapılabilir. Bu çalışmalar, hem platformun geliştirilmesine katkı sağlayacak, hem de platform üzerinden yapılacak derslerin niteliğini artıracaktır.

\section{KAYNAKÇA}

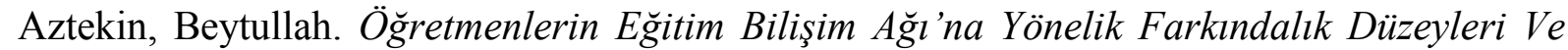
Tutumlarl Arasındaki İlişkinin İncelenmesi. Zonguldak: Zonguldak Bülent Ecevit Üniversitesi, Sosyal Bilimler Enstitüsü, Yüksek Lisans Tezi, 2020.

Bayyiğit Teker, Şeyma. Öğretmenlerin Teknolojik Pedagojik Alan Bilgisi (TPAB) Yeterlilikleri İle Ĕgitim Bilişim A $\breve{g}$ (EBA) Kullanımına Yönelik Tutumları Arasındaki İlişki. Balıkesir: Balıkesir Üniversitesi, Fen Bilimleri Enstitüsü, Yüksek Lisans Tezi, 2019.

Becit İşçitürk, Gökçe - Turan, Emine Zehra. "Din Kültürü ve Ahlak Bilgisi Öğretmenlerinin Eğitim Bilişim Ağı'na İlişkin Görüşleri”. Turkish Studies 13/29 (2018), 35-45. https://doi.org/10.7827/TurkishStudies.14299

Büyüköztürk, Şener vd. Eğitimde Bilimsel Araştırma Yöntemleri. Ankara: Pegem Akademi, 26. Basim, 2019.

Coşkunserçe, Ozan - İşçitürk, Gökçe Becit. "Eğitim Bilişim Ağı (EBA) Platformu Hakkında Öğrencilerin Farkındalığının Artırılmasına Yönelik Bir Durum Çalışması”. Eğitimde Nitel Araştırmalar Dergisi 7/1 (2019), 260-276.

Çakmak, Zafer - Taşkıran, Cengiz. "Sosyal Bilgiler Öğretmenlerinin Perspektifinden Eğitim Bilişim Ağı (EBA) Platformu”. Uluslararası Türk Ĕ̆itim Bilimleri Dergisi 2017/9 (2017), 284-295.

Doğan, Recai. "Cumhuriyet Dönemi İlahiyat Fakülteleri/Din Yükseköğretim: Tarihsel Gelişimi Problemleri ve Geleceği”. Türkiye'de Dinler Tarihinin Kurumsallaşması Sürecinde Prof. Dr. Abdurrahman Küçük. ed. Ahmet Hikmet Eroğlu. 231-250. Ankara: Berikan Yayınevi, 2016.

Ergün Bülbül, Serpil. "Çoklu Karşılaştırma Testleri ve Bir Örnek Uygulama”. Öneri Dergisi 3/14 (2000), 95-100.

Gür, Bekir S. vd. Eğitime Bakış 2018: İzleme ve Değerlendirme Raporu. Ankara: Eğitim Birsen Stratejik Araştırmalar Merkezi, 2018.

Kaptan, Saim. Bilimsel Araştırma ve İstatistik Teknikleri. Ankara: Tekışık, 11. Basım, 1998.

Karagöz, Yalçın. SPSS ve AMOS 23 Uygulamalı Istatistiksel Analizler. Ankara: Nobel, 2016. 
Karasar, Niyazi. Bilimsel Araştırma Yöntemi. Ankara: Nobel Yayın, 26. Basım, 2014.

Karasu, Teceli. "İmam Hatip Meslek ve DİKAP Dersi Öğretmenlerinin Eğitim Bilişim Ağı (EBA) İle İlgili Görüşleri” 7/2 (2018), 925-943.

MEB, Milli Eğitim Bakanlığı. "Fatih Projesi”. Erişim 17 Nisan 2021. http://fatihprojesi.meb.gov.tr

Şireci, Murat. Öğretmenlerin EBA Tutumlarının Farklı Değişkenler Açısından Incelenmesi. Kahramanmaraş: Kahramanmaraş Sütçü İmam Üniversitesi, Fen Bilimleri Enstitüsü, Yüksek Lisans Tezi, 2021.

Tabachnick, Barabara G. - Fidell, Linda S. Using Multivarite Statistics. Boston: Pearson, 6. Basim, 2013.

Uğurlu, Burcu - Gürsoy, Gülden. "Eğitim Bilişim Ağı Tutum Ölçeği Geliştirme Çalışması”. Eğitim Teknolojisi Kuram ve Uygulama 8/2 (2018), 35-66. https://doi.org/10.17943/etku.349499

Varışoğlu, Behice. "Öğretmenlerin Eğitim Bilişim Ağı (EBA) Tutumlarının İncelenmesi”. Turkish Studies-Social Sciences 14/6 (2019), 3511-3521. https://doi.org/10.29228/TurkishStudies.39294

Yıldız, Sevgi. "Sosyal Bilimlerde Örnekleme Sorunu: Nicel ve Nitel Paradigmalardan Örnekleme Kuramına Bütüncül Bir Bakış". Kesit Akademi Dergisi 3/11 (2017), 421-442. 